\title{
Improvement of Induction Motor State Observation: Extended Kalman Filter Versus Adaptive Luenberger Observer
}

\author{
YASSINE ZAHRAOUI \\ Mohammed 5 University \\ MOROCCO \\ zahraoui.yassin@gmail.com
}

MOHAMED AKHERRAZ

Mohammed 5 University

Mohammadia School of Engineering Mohammadia School of Engineering Mohammadia School of Engineering

Department of Electrical Engineering Department of Electrical Engineering Department of Electrical Engineering Street Ibn Sina, B.P 765 Agdal Rabat Street Ibn Sina, B.P 765 Agdal Rabat Street Ibn Sina, B.P 765 Agdal Rabat

\author{
MOROCCO \\ akherraz@emi.ac.ma
}

\author{
SARA ELBADAOUI \\ Mohammed 5 University \\ MOROCCO \\ elbadaouisara@gmail.com
}

Abstract: The sensor-less control is a major issue in control domain. The use of sensors has several downsides like high cost, fragility and low reliability. Furthermore, the physical environment sometimes, does not allow to use sensors. Due to the multiple variables and non-linearity of induction motor dynamics, the estimation of the rotor speed and flux without the measurement is still a very challenging subject. The main objective of this paper is to present a comparative study between two observer's structures, a full order adaptive observer based on Lyapunov theory and inherently extended Kalman filter which did not take the speed as adaptive quantity. Both of them are linked to a vector controlled induction motor drive. The effectiveness and estimation accuracy is investigated in detail by simulation results.

Key-Words: Sensor-less control, Extended Kalman filter, Adaptive Luenberger observer, Stochastic observer Received: December 5, 2019. Revised: April 6, 2020. Accepted: April 15, 2020. Published: May 4, 2020.

\section{Introduction}

Induction motor is the most commonly used electrical machine, it is cheaper, rugged and easier to maintain compared to other alternatives. It has two main parts: stator and rotor, stator is a stationary part and rotor is the rotating part. Stator is made by stacking thin slotted highly permeable steel lamination inside a steel or cast iron frame, winding passes through slots of stator. When a three phase AC current passes through it, something very interesting happens. It produces a rotating magnetic field, the speed of rotation of a magnetic field is known as synchronous speed. It's called an induction motor because electricity is inducted in rotor by magnetic induction rather than direct electric connection. To collapse such electric magnetic induction, to aid such electromagnetic induction, insulated iron core lamina are packed inside the rotor, such small slices of iron make sure that Eddy current losses are minimal. And this is another big advantage of three phase induction motors [1].

Regardless of the used control strategy, the measurement of speed and flux is an essential step for control design in electrical drives. In another cases, the implementation of control algorithms requires the knowledge of all the the state vector components. However, the use of sensors is associated with several disadvantages, like high cost, fragility and reduced reliability. In addition, sensors require a regular main- tenance, and in some applications, it is inappropriate to install them due to the physical and environmental constraints. A similar situation arises when a sensor breaks down [2].

The main proposed solution in literature is to avoid these difficulties of utilizing sensors by limiting their use and replacing them with software sensors. This strategy is known by sensor-less control theory in the automatic field, it takes a grand part in this domain. The software sensors are called estimators or observers. The objective of sensor-less control for electrical machines is to estimate mechanical speed or flux and its position [3]. The speed sensor-less control for AC drives has taken a big attention in industry application in the past decade, since it can reduce the cost and avoid the difficulty of installing mechanical sensors [4].

Over and above, the sensor-less control applications can improve the control system by reducing the number of the used sensors, reduce the cost of installation and cabling and increases the reliability of the drive. Thus, the observers remain an important area in process engineering. Many considerable researches have been proposed for the estimation of rotor speed and flux of electrical drives such as model reference adaptive system (MRAS) [5, 6], full order adaptive observers [7] and Kalman filter [8]. Moreover, the design of observers based on sliding mode methodology 
had an important discussion in many works.

For non-linear problems Kalman can overcome this difficulty by using a linearised approximation, where, the stochastic continuous time system must be expressed in the discrete form in order to fit with the structure of extended Kalman filter. The process of observation of the extended Kalman filter is given in two stages, prediction and filtering. The prediction stage is aimed to obtain the next predicted states and predicted state-error covariance, while in the filtering stage, the next estimated states is obtained as the sum of the next predicted states and a correction term. However, the high degree of complexity of EKF structure and the high system orders causes higher computational requirement (i.e. the sampling time). Thus, additional challenges and problems are introduced, such as the reduction of dynamic performance and the increase of harmonics. Nevertheless, the development of new processors technology (DSPs and FPGAs) solves this problem due to the powerful calculations processing [9].

\section{Induction motor drive modelling}

The induction motor has many state space mathematical models, each model is expressed by assuming a certain state vector. The modelling of AC machines is based mainly on the work of G. Kron, who gave birth to the concept of generalized machine as described in reference [10]. Park's model is a special case of this concept. It is often used for the synthesis of control laws and estimators. Described by a non linear algebra-differential system, Park's model reflects the dynamic behaviour of the electrical and electromagnetic modes of the asynchronous machine. It admits several classes of state representations. These model classes depend directly on the control objectives (torque, speed, position), the nature of the power source of the work repository and the choice of state vector components (flux or currents, stator or rotor). In this paper, the mathematical model of the machine in use is described in the stator fixed reference frame $(\mathrm{U}, \mathrm{V})$ (stationary frame) by assuming the stator currents and the rotor fluxes as state variables.

The mathematical model of a three-phase squirrel cage IM drive in $\alpha-\beta$ reference frame is:

$$
\left\{\begin{array}{l}
\dot{X}=\mathbf{A} X+\mathbf{B} U \\
Y=\mathbf{C} X
\end{array}\right.
$$

Where $X, U$ and $Y$ are the state, the input and the output vector respectively.

$X=\left[\begin{array}{llll}i_{s \alpha} & i_{s \beta} & \phi_{r \alpha} & \phi_{r \beta}\end{array}\right]^{t} ; U=\left[\begin{array}{ll}u_{s \alpha} & u_{s \beta}\end{array}\right]^{t} ; Y=\left[\begin{array}{ll}i_{s \alpha} & i_{s \beta}\end{array}\right]^{t}$

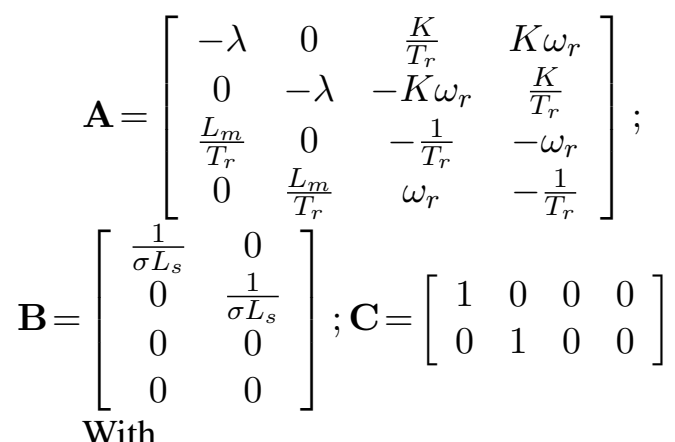

$\lambda=\frac{R_{s}}{\sigma \cdot L_{s}}+\frac{1-\sigma}{\sigma \cdot T_{r}} ; K=\frac{1-\sigma}{\sigma \cdot L_{m}} ; \sigma=1-\frac{L_{m}^{2}}{L_{s} \cdot L_{r}} ; T_{r}=\frac{L_{r}}{R_{r}}$

The state space mathematical model of the induction motor drive is shown in Figure 1.

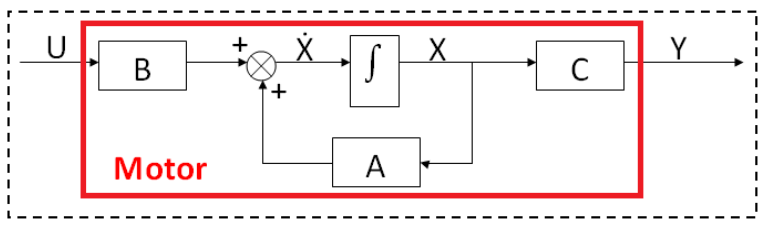

Figure 1: IM state space mathematical model

\section{Adaptive Luenberger observer for flux and speed estimation}

The adaptive flux observer is a deterministic type of observers based on a deterministic model of the system [11]. In this work, the adaptive Luenberger state observer (ALO) is used to estimate the flux components and the rotor speed by including an adaptive mechanism based on the Lyapunov theory [12]. In general, the equations of the ALO can be expressed as follow:

$$
\left\{\begin{array}{l}
\hat{\dot{X}}=\mathbf{A} \hat{X}+\mathbf{B} U+\mathbf{L}(Y-\hat{Y}) \\
\hat{Y}=\mathbf{C} \hat{X}
\end{array}\right.
$$

The symbol` ${ }^{\wedge}$ denotes the estimated value and $\mathbf{L}$ is the observer gain matrix. The mechanism of adaptation speed is deduced by Lyapunov theory [13]. The estimation error of the stator current and rotor flux, which is the difference between the observer and the model of the motor, is given by:

$$
\dot{e}=(\mathbf{A}-\mathbf{L C}) e+\Delta \mathbf{A} \hat{X}
$$

Where: $e=X-\hat{X}$

$$
\Delta \mathbf{A}=\mathbf{A}-\tilde{\mathbf{A}}=\left[\begin{array}{cccc}
0 & 0 & 0 & K \Delta \omega_{r} \\
0 & 0 & -K \Delta \omega_{r} & 0 \\
0 & 0 & 0 & -\Delta \omega_{r} \\
0 & 0 & \Delta \omega_{r} & 0
\end{array}\right]
$$


And: $\Delta \omega_{r}=\omega_{r}-\hat{\omega}_{r}$

Definition 1 We consider the following Lyapunov function:

$$
V=e^{t} \cdot e+\frac{\left(\Delta \omega_{r}\right)^{2}}{\lambda}
$$

Where $\lambda$ is a positive coefficient, its derivative is given as follow:

$$
\begin{array}{r}
\dot{V}=e^{t}\left[(\mathbf{A}-\mathbf{L} \mathbf{C})^{t}+(\mathbf{A}-\mathbf{L} \mathbf{C})\right] e \\
-2 K \Delta \omega_{r}\left(e_{i_{s \alpha}} \hat{\phi_{r \beta}}-e_{i_{s \beta}} \hat{\phi_{r \alpha}}\right)+\frac{2}{\lambda} \Delta \omega_{r} \dot{\hat{\omega}}_{r}
\end{array}
$$

With $\hat{\omega}_{r}$ is the estimated rotor speed. The adaptation law for the estimation of the rotor speed can be deduced by the equality between the second and third terms of Equation (6):

$$
\hat{\omega}_{r}=\int \lambda K\left(e_{i_{s \alpha}} \hat{\phi}_{r \beta}-e_{i_{s \beta}} \hat{\phi}_{r \alpha}\right) d t
$$

The feedback gain matrix $\mathbf{L}$ is chosen to ensure the fast and robust dynamic performance of the closed loop observer [14].

$$
\mathbf{L}=\left[\begin{array}{cc}
l_{1} & -l_{2} \\
l_{2} & l_{1} \\
l_{3} & -l_{4} \\
l_{4} & l_{3}
\end{array}\right]
$$

With $l_{1}, l_{2}, l_{3}$ and $l_{4}$ are given by: $l_{1}=\left(k_{1}-1\right)\left(\gamma+\frac{1}{T_{r}}\right) ; l_{2}=-\left(k_{1}-1\right) \hat{\omega}_{r}$ $l_{3}=\frac{\left(k_{1}^{2}-1\right)}{K}\left(\gamma-K \frac{L_{m}}{T_{r}}\right)+\frac{\left(k_{1}-1\right)}{K}\left(\gamma+\frac{1}{T_{r}}\right)$; $l_{4}=-\frac{\left(k_{1}-1\right)}{K} \hat{\omega}_{r}$

Remark $2 k_{1}$ is a positive coefficient obtained by pole placement approach; a wise choice was made for its value which is 1.06 in order to guarantee a fast response [15].

\section{Extended Kalman filter for flux and speed estimation}

\subsection{IM drive extended model}

The continuous model of the induction machine extended to the electrical rotational speed is represented by a non-linear system of state equations $[16,17]$ :

$$
\left\{\begin{array}{l}
\dot{X}_{e}(t)=f\left(X_{e}(t), U(t)\right)=\mathbf{A} X_{e}(t)+\mathbf{B} U(t) \\
Y(t)=h\left(X_{e}(t)\right)=\mathbf{C} X_{e}(t)
\end{array}\right.
$$

In which:

$X_{e}=\left[\begin{array}{ll}X & \Theta\end{array}\right]^{t}=\left[\begin{array}{lllll}i_{s \alpha} & i_{s \beta} & \phi_{r \alpha} & \phi_{r \beta} & \omega_{r}\end{array}\right]^{t} ;$

$$
Y=\left[\begin{array}{ll}
i_{s \alpha} & i_{s \beta}
\end{array}\right]^{t} ; U=\left[\begin{array}{ll}
u_{s \alpha} & u_{s \beta}
\end{array}\right]^{t}
$$

$$
\begin{gathered}
\text { With: } \\
A=\left[\begin{array}{ccccc}
-\gamma & 0 & \frac{\mu}{T_{r}} & \mu \omega_{r} & 0 \\
0 & -\gamma & -\mu \omega_{r} & \frac{\mu}{T_{r}} & 0 \\
\frac{L_{m}}{T_{r}} & 0 & 1-\frac{1}{T_{r}} & -\omega_{r} & 0 \\
0 & \frac{L_{m}}{T_{r}} & \omega_{r} & \frac{1}{T_{r}} & 0 \\
0 & 0 & 0 & 0 & 0
\end{array}\right] ; \\
B=\left[\begin{array}{cc}
\frac{1}{\sigma L_{s}} & 0 \\
0 & \frac{1}{\sigma L_{s}} \\
0 & 0 \\
0 & 0 \\
0 & 0
\end{array}\right]
\end{gathered}
$$

\subsection{Discretization of the continuous model}

The previous model of the induction machine must be discretized for the implementation of the extended Kalman filter. If quasi-constant control voltages are assumed over a sampling period $T_{s}$ as in reference [18], the discrete augmented state model can be approximated by:

$$
\left\{\begin{array}{l}
X_{e_{k+1}}=f\left(X_{e_{k}}, U_{k}\right)=\mathbf{A}_{\mathbf{d}} X_{e_{k}}+\mathbf{B}_{\mathbf{d}} U_{k} \\
Y_{k}=h\left(X_{e_{k}}\right)=\mathbf{C}_{\mathbf{d}} X_{e_{k}}
\end{array}\right.
$$

The matrices of this model are obtained by a limited development in Taylor series of order one [19]:

$\mathbf{A}_{\mathbf{d}} \approx e^{\mathbf{A} T_{s}}=I+\mathbf{A} T_{s} ; \mathbf{B}_{\mathbf{d}}=\mathbf{B} T_{s} ; \mathbf{C}_{\mathbf{d}}=\mathbf{C}$

This leads to :

$$
\begin{aligned}
\mathbf{A}_{\mathbf{d}} & =\left[\begin{array}{ccccc}
1-T_{s} \gamma & 0 & T_{s} \frac{\mu}{T_{r}} & T_{s} \mu \omega_{r} & 0 \\
0 & 1-T_{s} \gamma & -T_{s} \mu \omega_{r} & T_{s} \frac{\mu}{T_{r}} & 0 \\
T_{s} \frac{L_{m}}{T_{r}} & 0 & 1-\frac{T_{s}}{T_{r}} & -T_{s} \omega_{r} & 0 \\
0 & T_{s} \frac{L_{m}}{T_{r}} & T_{s} \omega_{r} & 1-\frac{T_{s}}{T_{r}} & 0 \\
0 & 0 & 0 & 0 & 1
\end{array}\right] ; \\
\mathbf{B}_{\mathbf{d}} & =\left[\begin{array}{cc}
T_{s} \frac{1}{\sigma L_{s}} & 0 \\
0 & T_{s} \frac{1}{\sigma L_{s}} \\
0 & 0 \\
0 & 0 \\
0 & 0
\end{array}\right]
\end{aligned}
$$

\subsection{Implementation of the EKF to the IM discrete system}

The application of the extended Kalman filter to the discrete system of the induction machine, taking into account the presence of state noise $W_{k}$ and measurement noise $V_{k}$. This leads to the following expres- 
sions:

$\left\{\begin{array}{l}X_{e_{k+1}}=f\left(X_{e_{k}}, U_{k}\right)+W_{k}=\mathbf{A}_{\mathbf{d}} X_{e_{k}}+\mathbf{B}_{\mathbf{d}} U_{k}+W_{k} \\ Y_{k}=h\left(X_{e_{k}}\right)+V_{k}=\mathbf{C}_{\mathbf{d}} X_{e_{k}}+V_{k}\end{array}\right.$

With:

$X_{e_{k+1}}=\left[\begin{array}{ll}X_{k} & \Theta_{k}\end{array}\right]^{t} ; Y_{k}=\left[\begin{array}{ll}i_{s \alpha_{k}} & i_{s \beta_{k}}\end{array}\right]^{t} ;$

$U_{k}=\left[\begin{array}{ll}u_{s \alpha_{k}} & u_{s \beta_{k}}\end{array}\right]^{t} ; W_{k}=\left[\begin{array}{ll}W_{x_{k}} & W_{\Theta_{k}}\end{array}\right]^{t}$

Similarly, the linearisation matrix $H_{k}$ is written as follows: $H_{k}=\left[\begin{array}{ccccc}1 & 0 & 0 & 0 & 0 \\ 0 & 1 & 0 & 0 & 0\end{array}\right]$

In the determination of the initial covariance matrix $P_{0 \mid 0}$, it is generally limited to the choice of elements on the diagonal. These elements are chosen in such a way that they correspond to the uncertainty about estimates of initial state variables.

Figure 2 shows the principle of an extended Kalman filter.

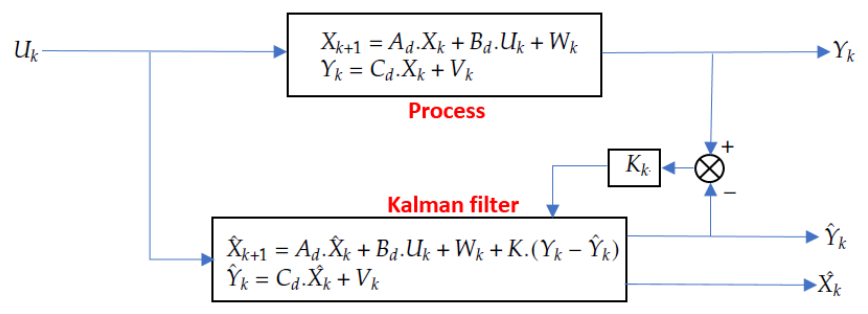

Figure 2: Extended Kalman filter principle

\subsubsection{Choice of covariance matrices $Q$ and $R$}

It is via these matrices that the various measured, predicted and estimated states will pass. Their goals are to minimize the errors associated with approximate modelling and the presence of noise on the measurements. This is the most difficult point of applying the Kalman filter to observation. The matrix $Q$ linked to the noises tainting the state, allows to adjust the estimated quality of the modelling and discretization. A strong value of $Q$ gives a high value of the gain $K$ stimulating the importance of the modelling and the dynamics of the filter. A high value of $Q$ can, however, create an instability of the observation. The matrix $R$ regulates the weight of the measurements. A high value indicates a great uncertainty of the measurement. On the other hand, a low value makes it possible to give a significant weight to the measurement [20].

$X_{e_{0 \mid 0}}=\left[\begin{array}{lllll}0 & 0 & 0 & 0 & 0\end{array}\right]^{t}$;
$P_{0 \mid 0}=\left[\begin{array}{ccccc}1 & 0 & 0 & 0 & 0 \\ 0 & 1 & 0 & 0 & 0 \\ 0 & 0 & 1 & 0 & 0 \\ 0 & 0 & 0 & 1 & 0 \\ 0 & 0 & 0 & 0 & 1\end{array}\right]$

$Q=\left[\begin{array}{ccccc}q_{11} & 0 & 0 & 0 & 0 \\ 0 & q_{22} & 0 & 0 & 0 \\ 0 & 0 & q_{33} & 0 & 0 \\ 0 & 0 & 0 & q_{44} & 0 \\ 0 & 0 & 0 & 0 & q_{55}\end{array}\right]$

$R=\left[\begin{array}{cc}r_{11} & 0 \\ 0 & r_{22}\end{array}\right]$

The parameters of the calibration matrices of the Kalman filter $Q$ and $R$ were chosen as follows:

$q_{11}=q_{22}=q_{33}=q_{44}=10^{-6} ; q_{55}=10^{6} ; r_{11}=r_{22}=10^{6}$.

The state space mathematical model of an observer is illustrated by Figure 3.

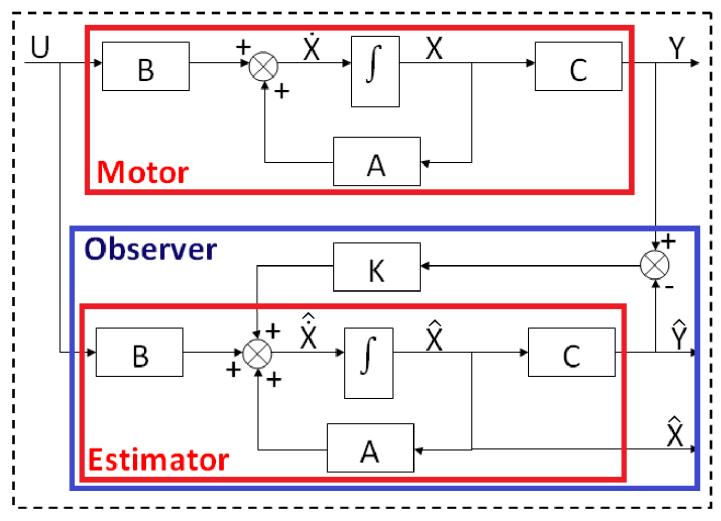

Figure 3: Observer state space mathematical model

Figure 4 shows the sensor-less vector controlled IM drive strategy.

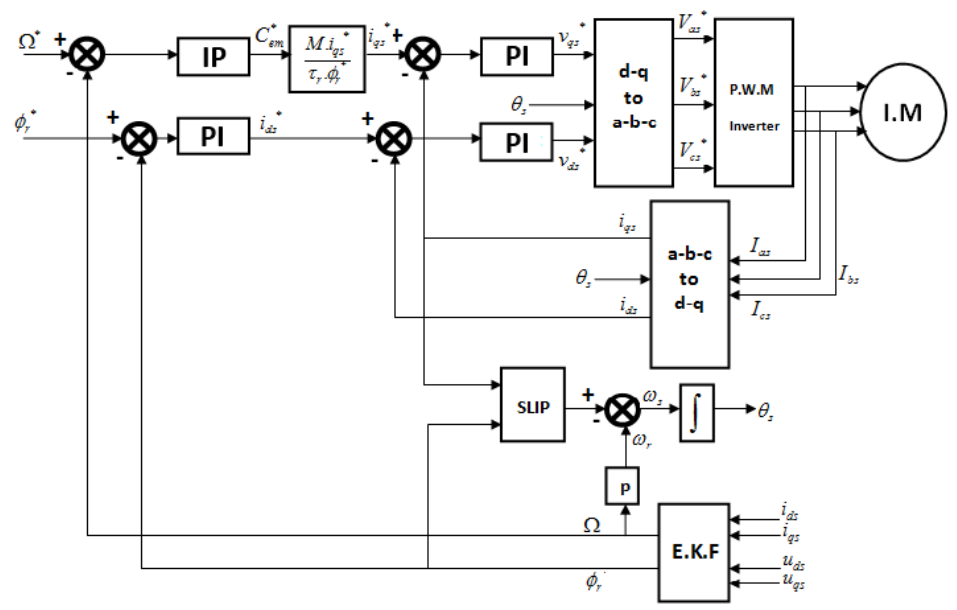

Figure 4: Proposed control scheme 


\section{Results and discussion}

In this section, an EKF is implemented in a sensor-less vector controlled IM drive. The EKF and ALO are designed to observe the motor state vector: $d-q$ stator phase current components $i_{d s}, i_{q s}, d-q$ rotor flux components $\phi_{d r}, \phi_{q r}$ and the mechanical speed $\omega_{r}$. The control law and the observer are implemented in MatLab/Simulink. And in order to show the system robustness against the external perturbation, a load torque of $10 \mathrm{~N} . \mathrm{m}$ is applied at $t_{1}=0.6 \mathrm{~s}$ and removed at $t_{2}=1.6 \mathrm{~s}$.

Figures 5 to 18 illustrate a performance comparison between the two observers: EKF in the left and ALO in the right. Figure 5 shows the speed response according to a step reference of $100 \mathrm{rad} / \mathrm{s}$. Both observers show good dynamic at starting up and the speed regulation loop rejects the applied load disturbance quickly. The two observers kept the same fast speed response since the same PI speed controller is used for both speed loops, there is no difference in the transient response. The system response time is very quick and does not exceed $0.2 \mathrm{~s}$.

Figure 6 shows the rotor flux response, it achieves the reference which is $1 \mathrm{~Wb}$ very quickly. Even the step reference starts at $0.2 \mathrm{~s}$, the rotor flux response is independent to the speed application. It is reaching the reference very rapidly at the starting up. Then, Figure 7 shows the torque responses with the load application. At the beginning, the speed controller operates the system at the physical limit since the step reference is the hardest for most control processes.

Until now, no apparent difference in the performance of the two observers, Figures 9 to $\mathbf{1 8}$ will reveal this difference. Figures $\mathbf{9}$ and $\mathbf{1 0}$ illustrate respectively the observed stator current components $i_{d s}$ and $i_{q s}$. We can notice clearly the superiority of the EKF, no fluctuations seen around the reference. EKF uses a series of measurements containing noise and other inaccuracies contrary to ALO that employs only free noise measurements. Figures 11 and 12 illustrate respectively the observed rotor flux components $\phi_{d r}$ and $\phi_{q r}$. No fluctuations seen around the reference for both observers, only a small static error of observation. Finally, Figures $\mathbf{1 3}$ to $\mathbf{1 8}$ illustrate the static error of all the observed components: the machine state parameters, the rotor flux and the mechanical speed.

All the quantities observed by the EKF are filtered and precise, the EKF is a very good observer for the systems that present any kind of noise. It will exploit the noise in order to estimate the quantity. It's very important to note that the EKF observation process is given in two stages: prediction and filtering.

\section{Conclusion}

All the closed-loop observers are classified as deterministic observers, they can be easily corrupted by measuring noise and require parameter adaptation algorithms. The Kalman filter observers have high convergence rate and good disturbance rejection, which can take into account the model uncertainties, random disturbances, computational inaccuracies and measurement errors. These properties are the advantages of extended Kalman filters over other estimation methods. For these reasons, they had wide application in sensor-less control in spite of their computational complexity. For non-linear problems, Kalman filtering can overcome this difficulty by using a linearised approximation, where, the stochastic continuous time system must be expressed in the discrete form in order to fit with the structure of the EKF. The EKF observation process is given in two stages, prediction and filtering. The prediction stage is aimed to obtain the next predicted states and predicted state-error covariance, while in the filtering stage, the next estimated states is obtained as the sum of the next predicted states and a correction term.

However, the high degree of complexity of EKF structure and the high system orders cause a higher computational requirement (the sampling time). Thus, additional challenges and problems are introduced, such as the reduction of dynamic performance and the increase of harmonics. Nevertheless, the development of new processors technology (DSPs and FPGAs) solves this problem due to the powerful calculations processing.

\section{Appendix}

Table 1 lists the rated power and parameters of the used machine.

Table 1: IM drive rated power and parameters

\begin{tabular}{|c|c|}
\hline Rated power & $3 \mathrm{~kW}$ \\
\hline Voltage & $380 \mathrm{~V}$ \\
\hline Frequency & $50 \mathrm{~Hz}$ \\
\hline Pair pole & 2 \\
\hline Rated speed & $1440 \mathrm{rpm}$ \\
\hline Stator resistance & $2.2 \Omega$ \\
\hline Rotor resistance & $2.68 \Omega$ \\
\hline Stator inductance & $0.229 \mathrm{H}$ \\
\hline Rotor inductance & $0.229 \mathrm{H}$ \\
\hline Mutual inductance & $0.217 \mathrm{H}$ \\
\hline Moment of inertia & $0.047 \mathrm{~kg} \cdot \mathrm{m}^{2}$ \\
\hline Viscous friction coefficient & $0.004 \mathrm{N.s} / \mathrm{rad}$ \\
\hline
\end{tabular}



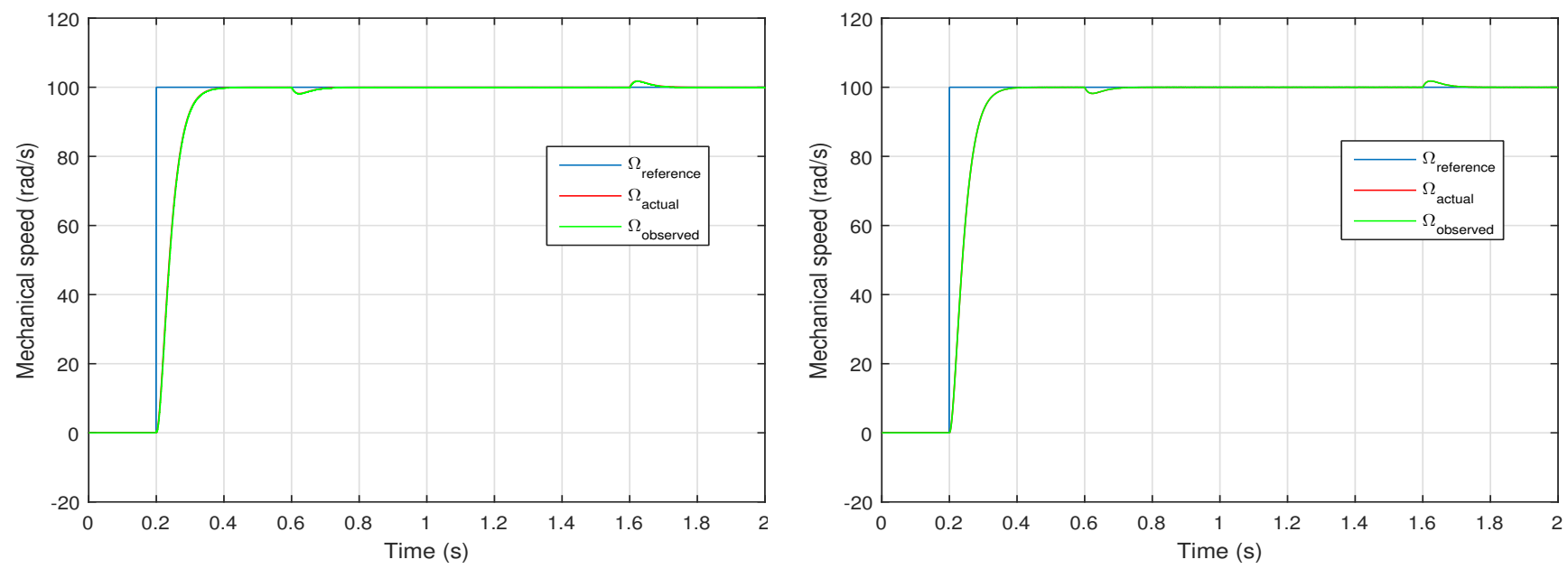

Figure 5: Speed response
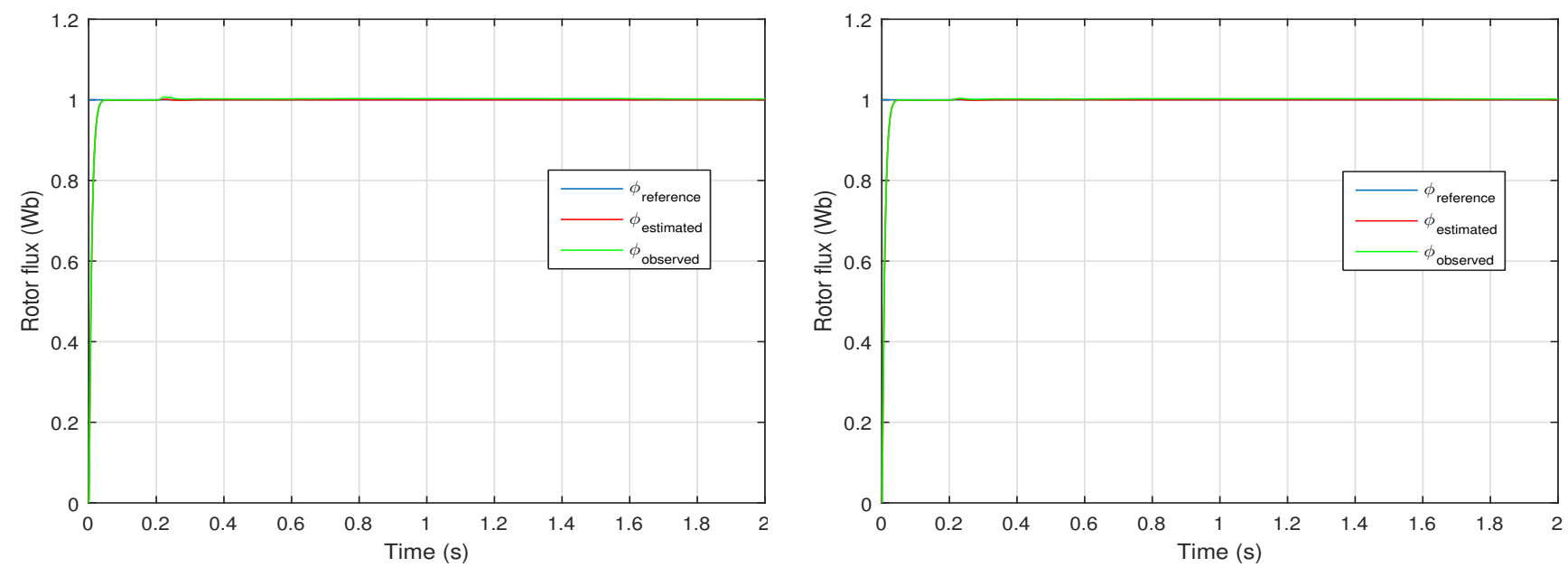

Figure 6: Rotor flux response
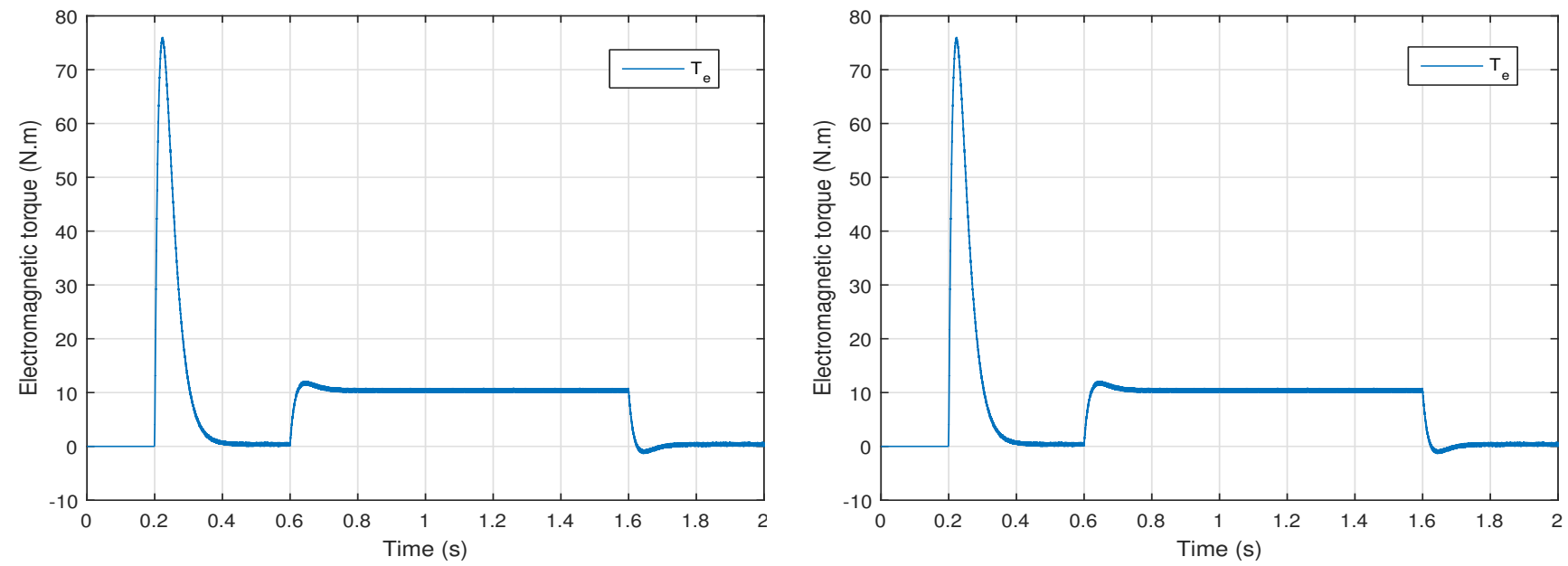

Figure 7: Electromagnetic torque response 

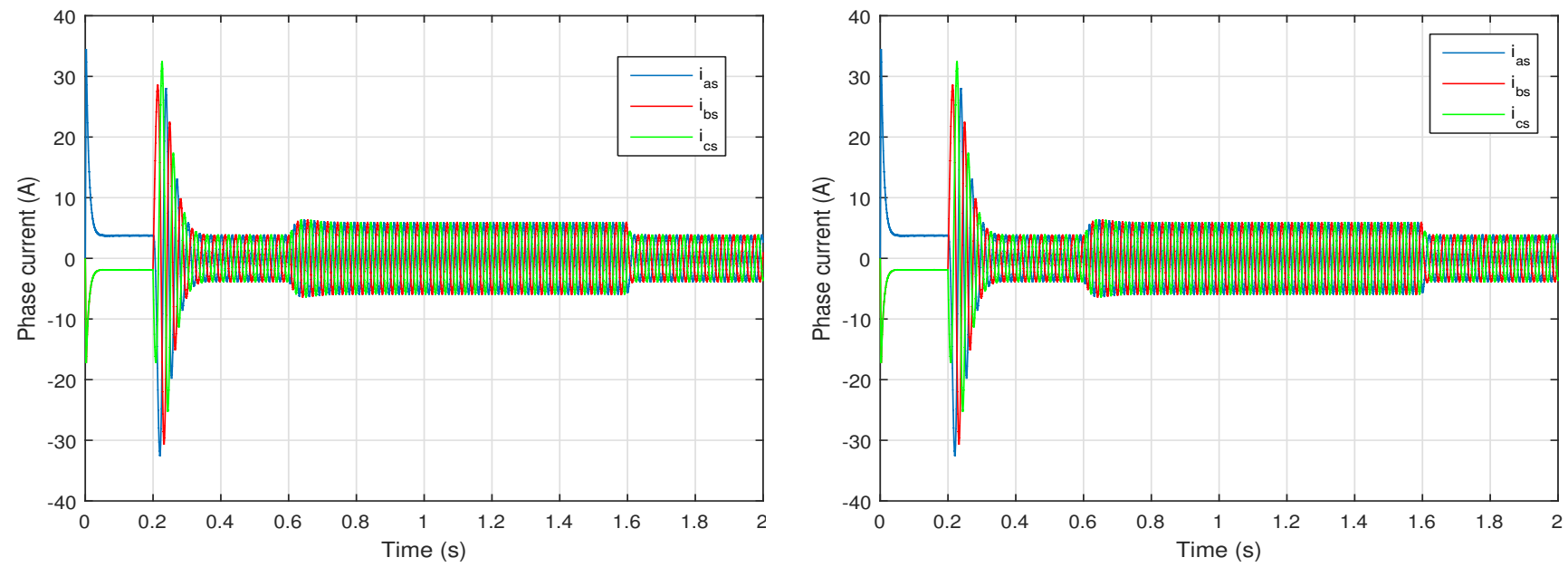

Figure 8: Stator phase currents response
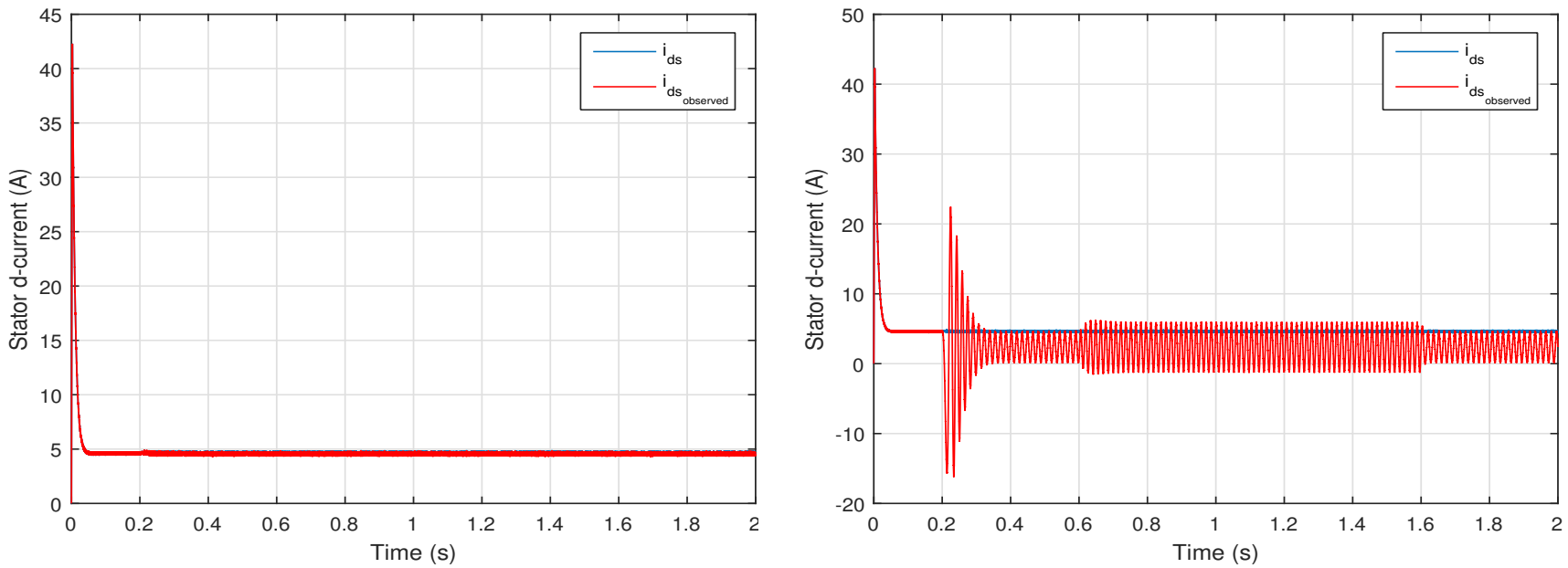

Figure 9: $i_{d s}$ current response
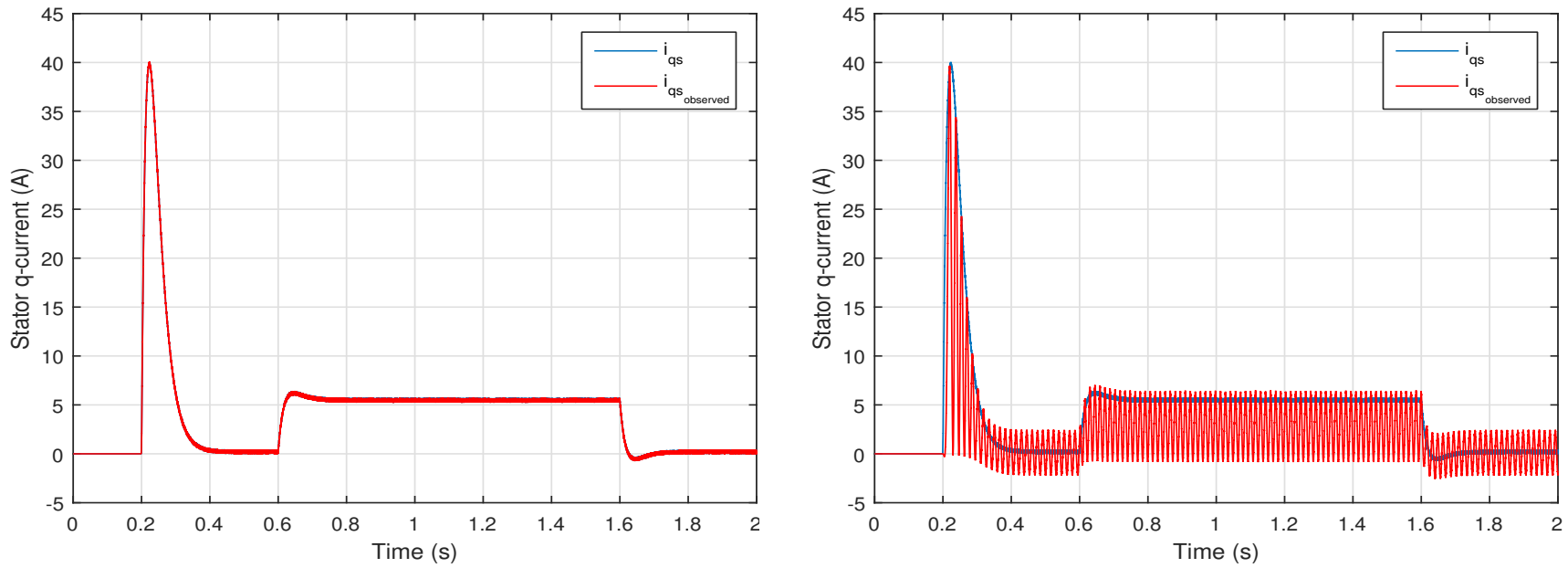

Figure 10: $i_{q s}$ current response 

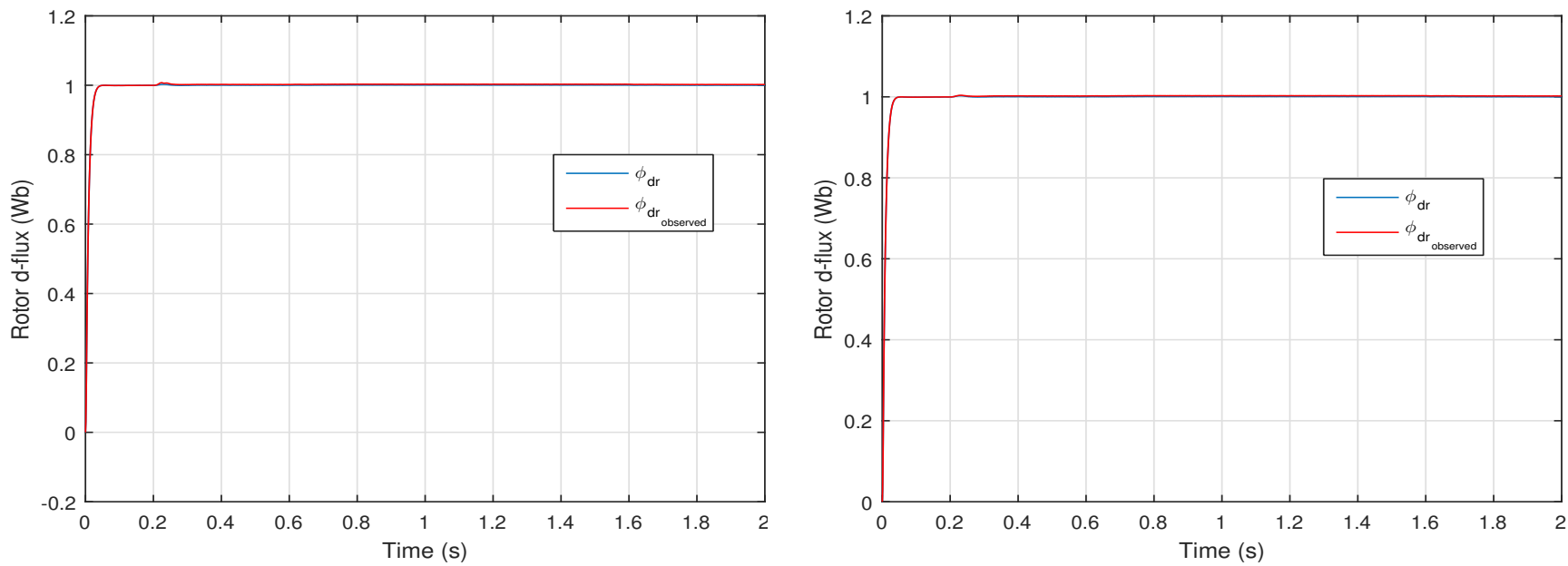

Figure 11: $\phi_{d r}$ flux response
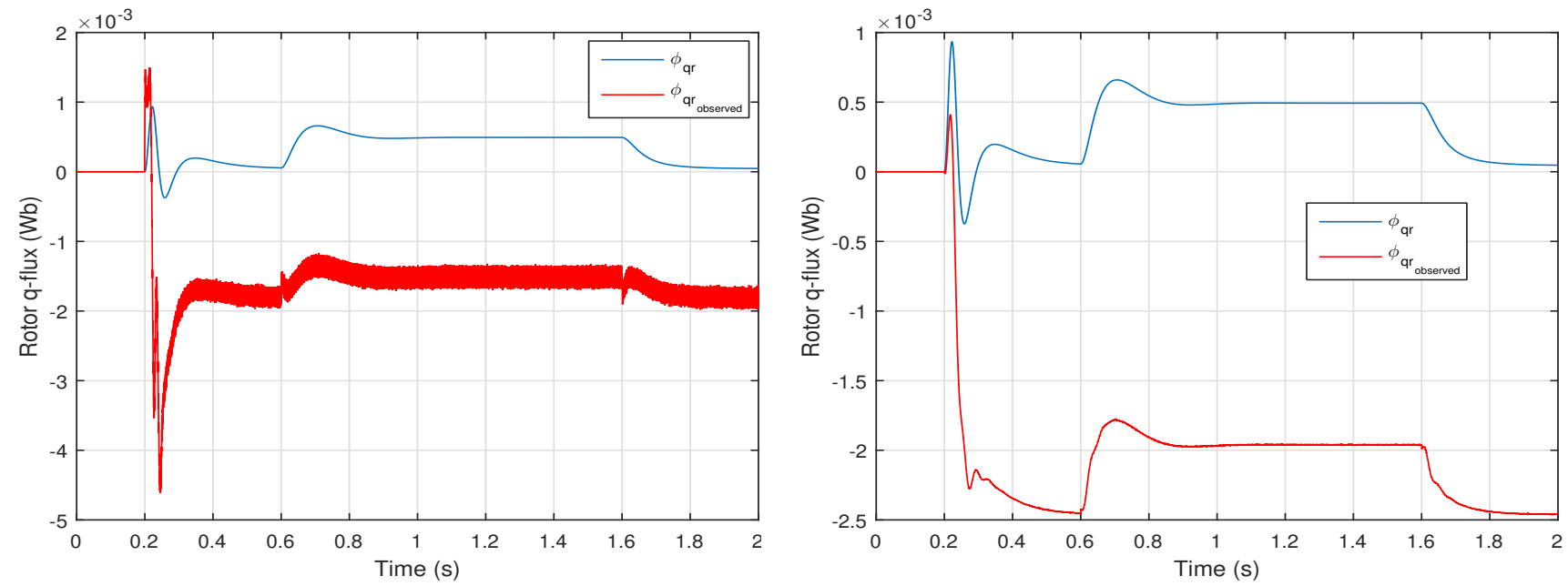

Figure 12: $\phi_{q r}$ flux response
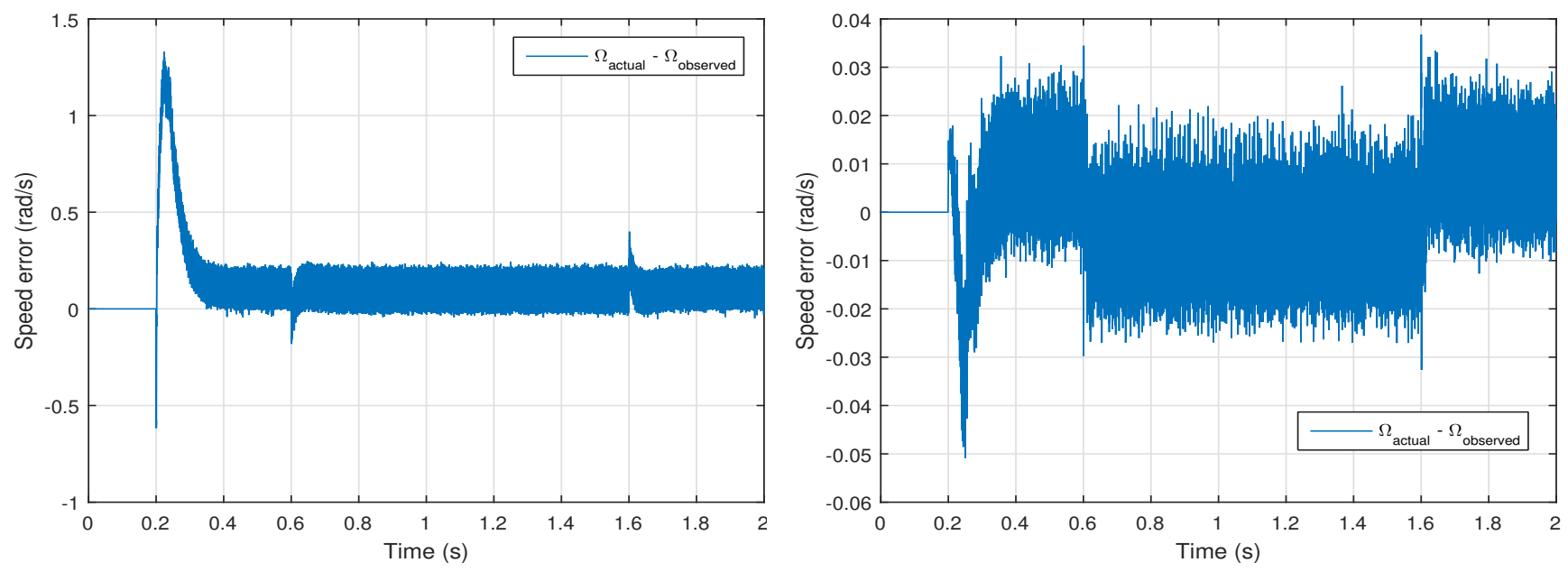

Figure 13: Mechanical speed error 

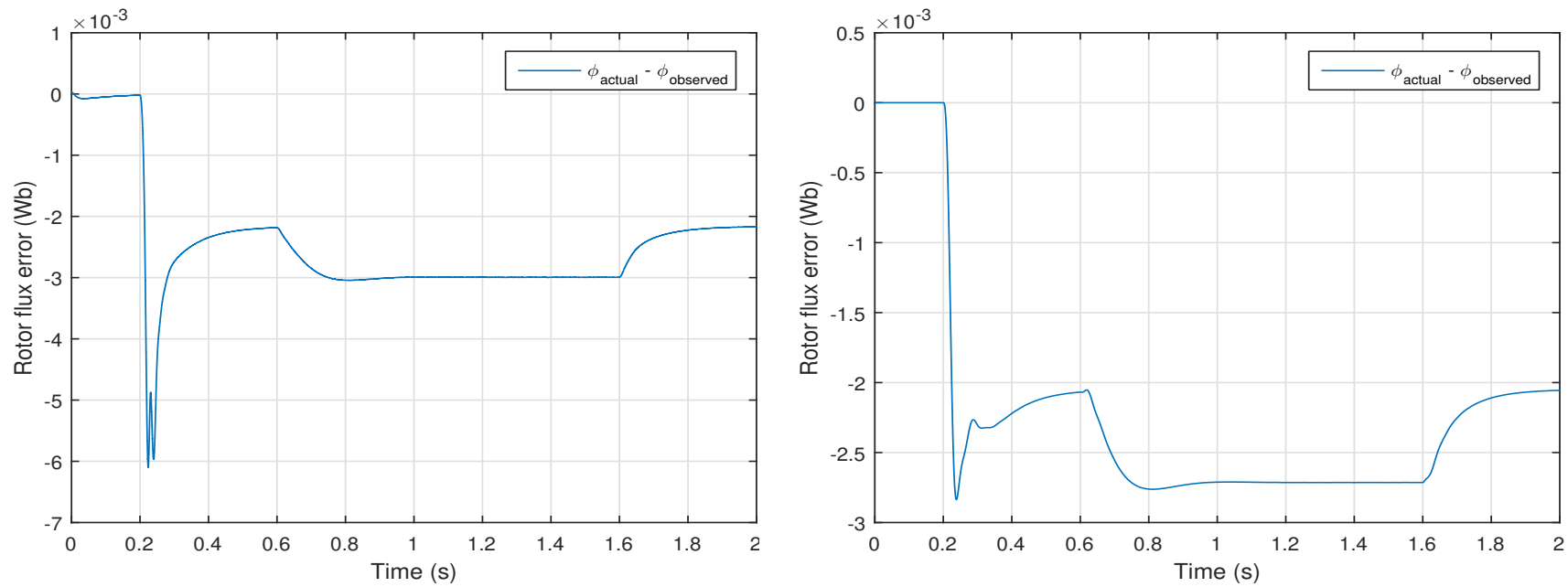

Figure 14: Rotor flux error
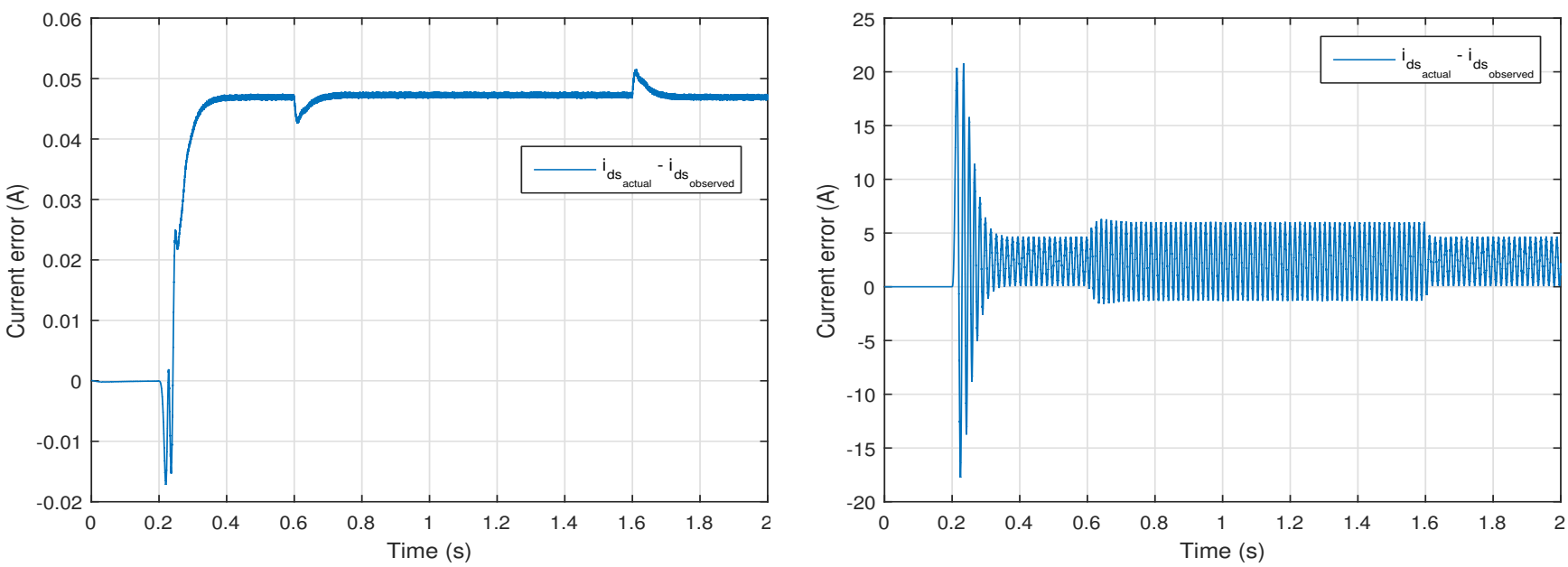

Figure 15: $i_{d s}$ component error
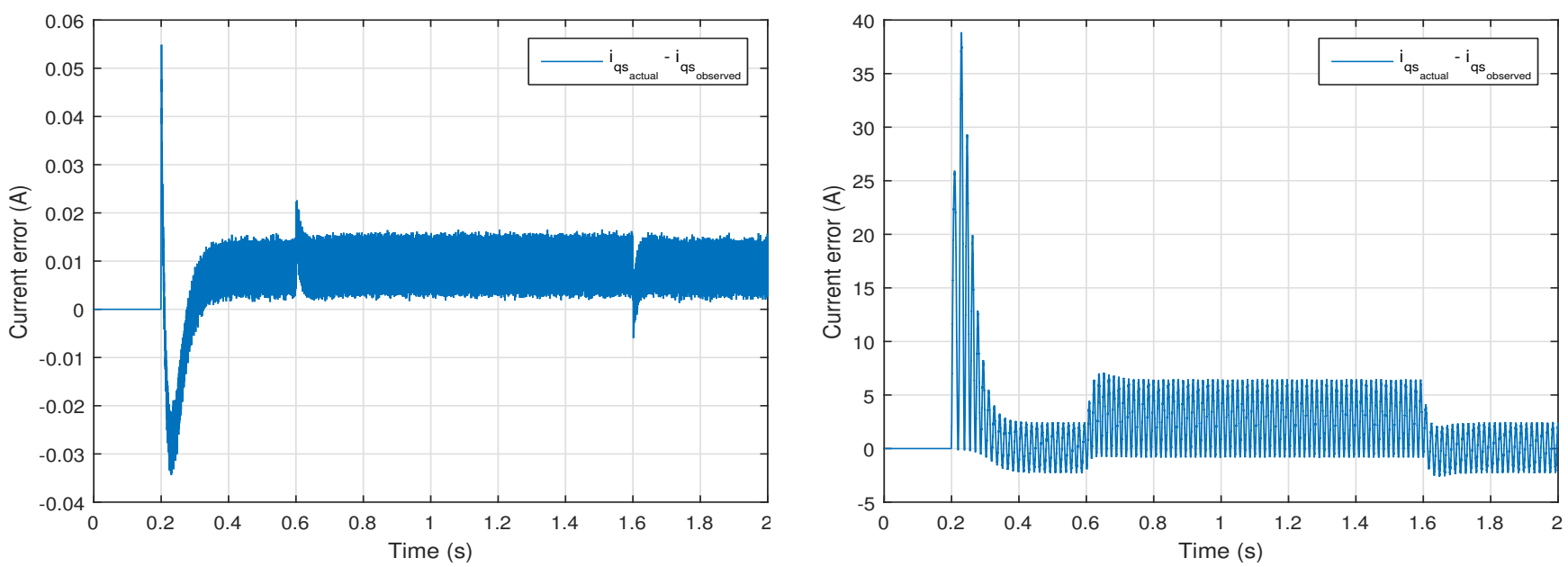

Figure 16: $i_{q s}$ component error 

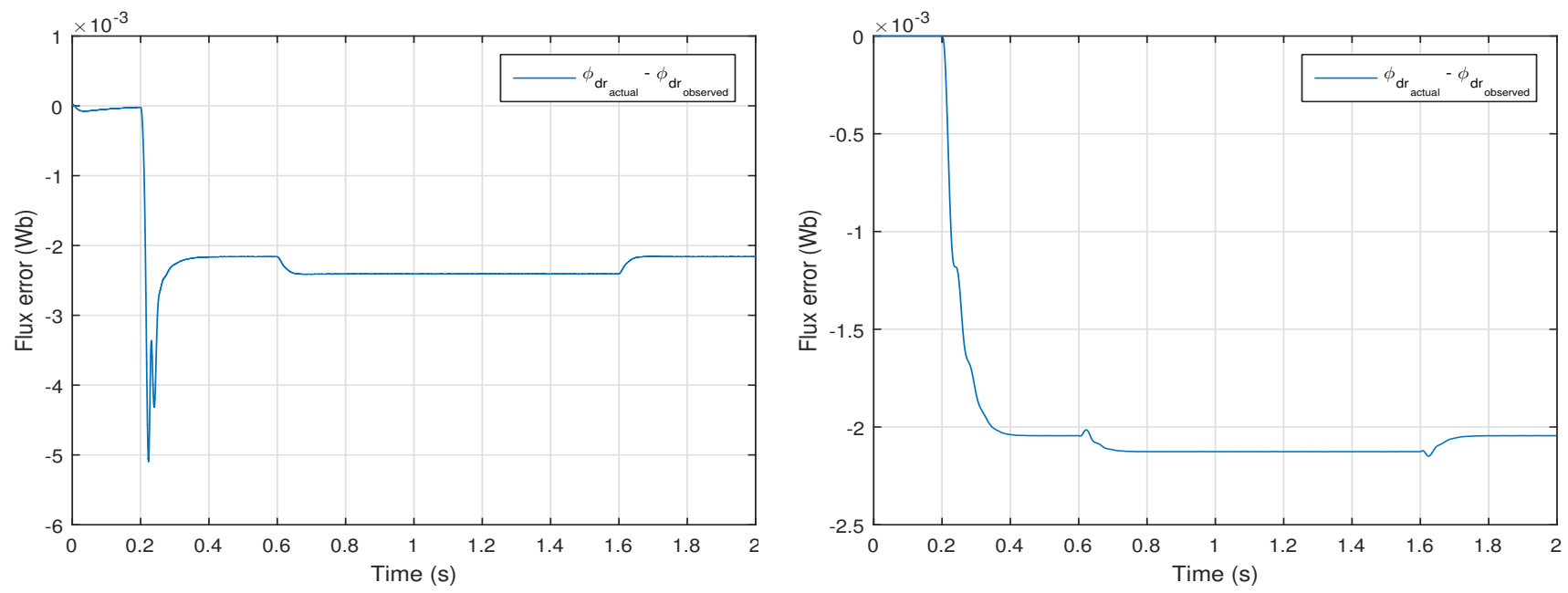

Figure 17: $\phi_{d r}$ component error
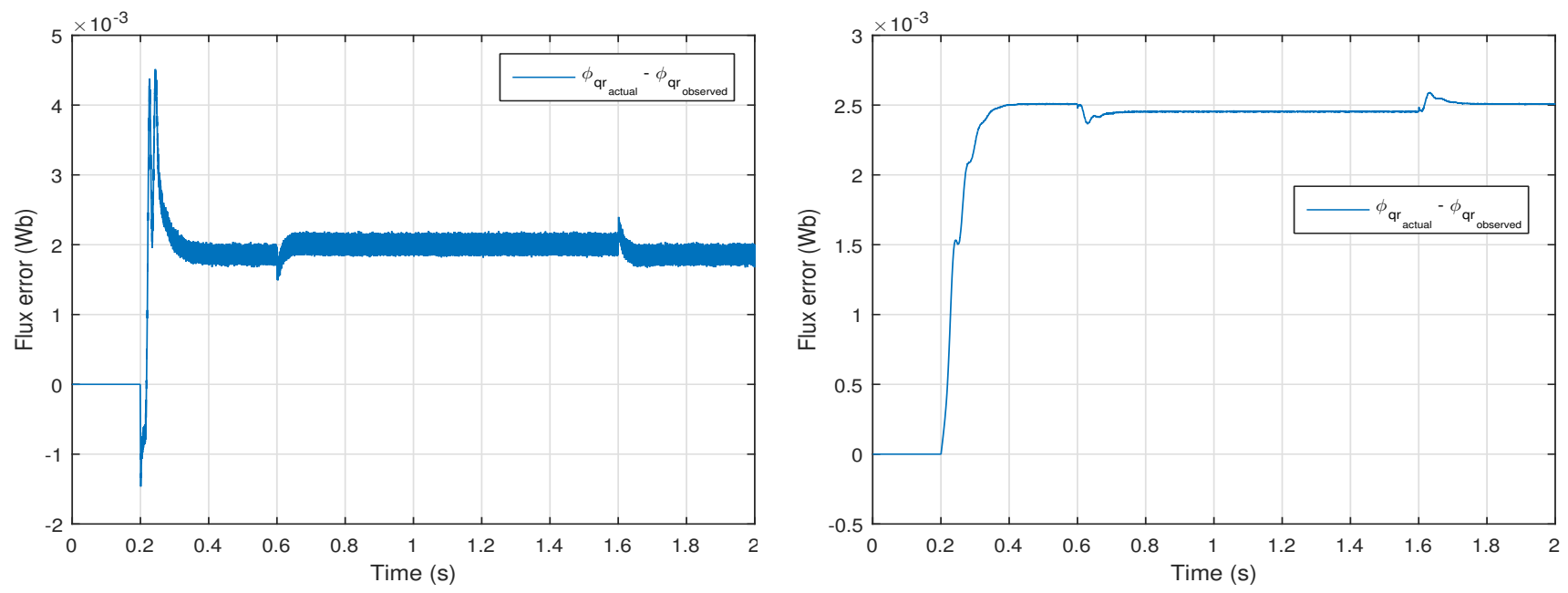

Figure 18: $\phi_{q r}$ component error

\section{References:}

[1] B. Wu and M. Narimani, High-power converters and AC drives, John Wiley and Sons, vol. 59, 2017.

[2] M. Taoussi, M. Karim, B. Bossoufi, D. Hammoumi, C. El Bakkali, A. Derouich and N. El Ouanjli, Low-Speed Sensorless Control for Wind Turbine System, WSEAS transactions on systems and control, pp. 405-417, 2017.

[3] Y. Zahraoui, M. Akherraz and C. Fahassa, Induction motor DTC performance improvement by reducing torque ripples in low speed, UPB Sci. Bull. Ser. C, vol. 81, no 3, pp. 249-260, 2019.

[4] Y. Zahraoui, M. Akherraz, C. Fahassa and S. Elbadaoui, Induction motor harmonic reduction using space vector modulation algorithm, Bulletin of Electrical Engineering and Informatics, vol. 9, no 2, 2020.

[5] R. Kumar, S. Das, P. Syam, and A. K. Chattopadhyay, Review on model reference adaptive system for sensorless vector control of induction motor drives, IET Electric Power Applications, vol. 9, pp. 496-511, July 2015.

[6] A. N. Smith, S. M. Gadoue, and J.W. Finch, Improved Rotor Flux Estimation at Low Speeds for Torque MRAS-Based Sensorless Induction Motor Drives, IEEE Transactions on Energy Conversion, vol. 31, pp. 270-282, Mar. 2016.

[7] M. H. Holakooie, M. Ojaghi and A. Taheri, Fullorder Luenberger observer based on fuzzy-logic control for sensorless field-oriented control of a 
single-sided linear induction motor, ISA transactions, 60, pp. 96-108, 2016.

[8] Z. Yin, G. Li, Y. Zhang, J. Liu, X. Sun and Y. Zhong, A speed and flux observer of induction motor based on extended Kalman filter and Markov chain, IEEE Transactions on Power Electronics, 32(9), pp. 7096-7117, 2016.

[9] F. Alonge, T. Cangemi, F. D’Ippolito, A. Fagiolini and A. Sferlazza, Convergence analysis of extended Kalman filter for sensorless control of induction motor, IEEE Transactions on Industrial Electronics, 62(4), pp. 2341-2352, 2014.

[10] G. Kron, Generalized theory of electrical machinery, Transactions of the American Institute of Electrical Engineers, vol. 49, no. 2, pp. 666683, 1930.

[11] Y. Zahraoui, M. Akherraz and C. Fahassa, Induction Motor Performance Improvement Using Twelve Sectors DTC and Fuzzy Logic Speed Regulation, WSEAS transactions on systems and control, vol. 15, no 6, pp. 47-56, 2020.

[12] H. S. Hoang and R. Baraille, On Estimation of Model Error by an Adaptive Filter, WSEAS transactions on systems and control, vol. 14, pp. 158-168, 2019.

[13] M. Jouili, K. Jarray, Y. Koubaa and M. Boussak, Luenberger state observer for speed sensorless ISFOC induction motor drives, Electric Power Systems Research, 89, pp. 139-147, 2012.

[14] A. Bennassar, A. Abbou, M. Akherraz and M. Barara, Sensorless backstepping control using an adaptive Luenberger observer with three levels NPC inverter, International Journal of Computer, Electrical, Automation, Control and Information Engineering, 7(8), pp. 1171-1177, 2013.

[15] C. Djamila, M. Yahia and T. Ali, Simultaneous estimation of rotor speed and stator resistance in sensorless indirect vector control of induction motor drives using a Luenberger observer, International Journal of Computer Science Issues (IJCSI), 9(3), 325, 2012.

[16] L. Wanmin, W. Yang, Z. Yaping and Y. Yunzi, Kalman Filter Method Based Vehicle Mass Estimation for Automobile Suspension System, International Journal of Circuits, Systems and Signal Processing, vol. 13, pp. 344-351, 2019.

[17] C. Lascu, I. Boldea, and F. Blaabjerg, Comparative study of adaptive and inherently sensorless observers for variable-speed inductionmotor drives, IEEE Transactions on Industrial Electronics, vol. 53, pp. 57-65, Feb. 2006.
[18] Y. Zahraoui, A. Bennassar, M. Akherraz and A. Essalmi, Indirect vector control of induction motor using an extended Kalman observer and fuzzy logic controllers, In 3rd International Renewable and Sustainable Energy Conference (IRSEC), pp. 1-6. IEEE, 2019.

[19] Y. Zahraoui, C. Fahassa, M. Akherraz and A. Bennassar, Sensorless vector control of induction motor using an EKF and SVPWM algorithm, In 5th International Conference on Multimedia Computing and Systems (ICMCS), pp. 588-593, Sept. 2016.

[20] M. Habibullah and D. D. C. Lu, A speedsensorless FS-PTC of induction motors using extended Kalman filters, IEEE Transactions on Industrial Electronics, 62(11), pp. 6765-6778, 2015. 